\title{
Can We Reduce the Number of Low-Birth-Weight Babies? The Cuban Experience
}

\author{
Nacyra Bonet Lopez ${ }^{\mathrm{a}}$ Imti Choonara ${ }^{\mathrm{b}}$ \\ a Department of Provincial Health, Camaguey, Cuba; berbyshire Children's Hospital, University of Nottingham, \\ Derby, UK
}

\section{Key Words}

Low birth weight $\cdot$ Preterm birth $\cdot$ Intrauterine growth

retardation $\cdot$ Mortality $\cdot$ Cuba

\begin{abstract}
Low-birth-weight (LBW) infants have a significantly greater mortality than other babies, not only within the neonatal period but also in infancy and early childhood. Babies are LBW either because they are preterm or they have experienced intrauterine growth retardation. Reducing the prevalence of $L B W$ babies is important in reducing child and infant mortality. Risk factors for prematurity and intrauterine growth retardation are well established. Socioeconomic conditions and nutrition during pregnancy are two key factors. Interventions to reduce the prevalence of LBW infants in developed countries have usually been unsuccessful. A few studies in developing countries have, however, achieved positive results. Cuba has managed to reduce the prevalence of LBW infants and their model of healthcare in relation to achieving this is described. Key features of the Cuban healthcare system are that it is both free and universal, and additionally there is a strong emphasis on primary healthcare. It is likely that a similar approach in both developing countries and disadvantaged communities in developed countries
\end{abstract}

would reduce the prevalence of LBW babies. This would have a major impact in relation to reducing infant mortality rates.

Copyright $\odot 2008$ S. Karger AG, Basel

\section{Introduction}

Low birth weight (LBW) is defined by the World Health Organization (WHO) as a birth weight of $<2.5 \mathrm{~kg}$ irrespective of gestational age [1]. This definition was agreed at the 29th World Health Assembly in 1976 [1]. LBW infants have a significantly greater mortality than other babies. Worldwide each year there are more than 20 million LBW infants born and they account for over $15 \%$ of all births. Over $95 \%$ of these births occur in developing countries. There are two main causes of LBW babies. These are preterm birth (before 37 weeks' gestational age) [1] and intrauterine growth retardation (IUGR). Both the WHO and UNICEF recognise the importance of reducing the number of LBW infants as an important contribution to the Millennium Development Goal for reducing child mortality.

The importance of birth weight is illustrated by recent data from the USA which looks at infant mortality rates 
Table 1. Prevalence of LBW infants [1] and infant mortality rates [3] in several countries

\begin{tabular}{lll}
\hline Country & $\begin{array}{l}\text { \% LBW infants } \\
(2000)\end{array}$ & $\begin{array}{l}\text { Infant mortality rate } \\
(2005)\end{array}$ \\
\hline Finland & 4 & 3 \\
Canada & 6 & 5 \\
Cuba & 6 & 5 \\
UK & 8 & 5 \\
USA & 8 & 7 \\
Jamaica & 9 & 17 \\
Bangladesh & 30 & 54 \\
India & 30 & 56 \\
\hline
\end{tabular}

${ }^{1}$ Per 1,000 live births.

Table 2. Risk factors for LBW

\begin{tabular}{|c|c|c|}
\hline & $\begin{array}{l}\text { Prema- } \\
\text { turity }\end{array}$ & IUGR \\
\hline \multicolumn{3}{|l|}{ Society } \\
\hline Poor socioeconomic conditions & + & + \\
\hline Very young maternal age & + & + \\
\hline Advanced maternal age & + & - \\
\hline Lack/poor maternal education & + & + \\
\hline Quality of antenatal care & + & + \\
\hline Working long hours during pregnancy & + & - \\
\hline Short inter-pregnancy interval & + & - \\
\hline Single marital status & + & + \\
\hline High altitudes & - & + \\
\hline \multicolumn{3}{|l|}{ Nutrition } \\
\hline Inadequate calorie intake & - & + \\
\hline Low pre-pregnancy weight & + & + \\
\hline Poor gestational weight gain & - & + \\
\hline Nutritional deficiencies (iron, folate or zinc) & + & - \\
\hline Maternal short stature & - & + \\
\hline \multicolumn{3}{|l|}{ Mental health } \\
\hline Stress and anxiety & + & - \\
\hline Depression & $?$ & - \\
\hline \multicolumn{3}{|l|}{ Toxicology } \\
\hline Cigarette smoking & + & + \\
\hline Environmental toxins & + & + \\
\hline \multicolumn{3}{|l|}{ Medical } \\
\hline General morbidity, episodic illness & - & + \\
\hline Hypertension & + & + \\
\hline Infections & + & - \\
\hline Inflammation & + & - \\
\hline Multiple gestations & + & - \\
\hline Previous preterm birth & + & - \\
\hline Periodontal disease & $?$ & - \\
\hline
\end{tabular}

(IMRs) in relation to a variety of factors [2]. The IMR is 25 times greater for LBW infants than for babies weighing $\geq 2.5 \mathrm{~kg}$. For infants weighing $<1.5 \mathrm{~kg}$, the IMR is 108 times greater. This is as expected as these are the highly preterm infants where survival rates are low. The American data does, however, also point out that the IMR for babies with a birth weight between 2.25 and $2.5 \mathrm{~kg}$ is almost 5 times greater than the IMR for babies weighing $\geq 2.5 \mathrm{~kg}$ [2].

Despite the fact that more than half the infants in the developing world are not weighed at birth, the WHO and UNICEF have developed methods to estimate the percentage of LBW infants born each year in most countries [1]. There is considerable variation between countries in the percentage of LBW babies and this is illustrated in table 1. Table 1 also shows data for the IMR, and it is clear that there is a strong correlation between the percentage of LBW births and the IMR [3]. Cuba, which is a poor country, has the same percentage of LBW infants as Canada, which is far richer. This review will look at the aetiology of LBW infants and the Cuban experience of reducing the number of LBW infants.

\section{Aetiology}

There is considerable overlap between risk factors for prematurity and risk factors for IUGR. Poverty is associated with an increased risk for an LBW birth [4]. This is probably associated with a variety of factors. These include poor nutrition, an increased prevalence of cigarette smoking and drug abuse, alongside a very young maternal age and an inadequate education in relation to pregnancy and poor diet. The most systematic review of the determinants of LBW is the extensive study by Kramer [5] that was published 20 years ago. Kramer identified the following risk factors for (i) the early onset of labour and subsequent birth of a preterm infant and (ii) for IUGR and subsequent birth of an LBW baby: poor socioeconomic conditions; low weight prior to pregnancy; very young maternal age; lack of/poor maternal education, and cigarette smoking. He also established that the following were risk factors for IUGR: poor calorie intake; general morbidity, episodic illness during pregnancy; poor weight gain during pregnancy, and short stature.

Subsequent research has confirmed many of the risk factors identified by Kramer and also confirmed some of the possible risk factors previously identified (table 2). These studies have looked at both society issues such as poor maternal socioeconomic status [6] and low levels of 
maternal education [7] as well as medical issues such as maternal hypertension, placenta previa and placental abruption [8-11]. The importance of antenatal care has been highlighted in an American study which suggested that women who received no antenatal care had an almost 4 times greater risk of delivering an LBW baby [12].

Air pollution appears to be associated with both IUGR and prematurity [13]. A systematic review of the literature suggests that there is a link between polycyclic aromatic hydrocarbons and IUGR, but the timing of exposure and precise identification of the relevant pollutants has not yet been established [14].

\section{Interventions}

Despite the fact that the aetiology of LBW babies has been known for over 20 years, interventions in many countries have usually been unsuccessful in both reducing IUGR and preventing preterm births. A systematic review of 126 trials evaluating 36 prenatal interventions to prevent or treat IUGR identified only three interventions which had been shown to be beneficial [15]. These included (1) the cessation of smoking, (2) nutritional supplementation during pregnancy, and (3) the treatment of malaria during pregnancy. It is important to recognise that although only three interventions had been shown to be beneficial, this did not mean that the other 33 interventions are definitely not of benefit. Many of the trials had inadequate sample sizes or were poorly randomised. The authors identified supplementation with zinc, folate and magnesium as areas that required further research. They also commented that combinations of several interventions may be of benefit. The same group did a systematic review of nutritional and antimicrobial interventions to prevent preterm births [16]. They identified that the treatment of asymptomatic bacteriuria during pregnancy reduced the incidence of both preterm birth and delivery of an LBW infant.

In contrast, a trial in rural Gambia demonstrated that nutritional supplementation during pregnancy in mothers at risk resulted in a mean increase in birth weight of $136 \mathrm{~g}$ [17]. This small increase in mean birth weight reduced the prevalence of LBW infants from 17 to $11.1 \%$. This small study also reported a substantial reduction in the prevalence of still births and in early neonatal mortality [17]. It is important to recognise that several studies have documented a small increase in birth weight in disadvantaged communities [18]. It has been suggested that an increase of $100 \mathrm{~g}$ in the mean birth weight may be as-
Table 3. LBW births in Cuba [23]

\begin{tabular}{lll}
\hline Year & LBW births & Live births, \% \\
\hline 1978 & 15,115 & 10.4 \\
1980 & 13,178 & 9.7 \\
1985 & 14,693 & 8.2 \\
1990 & 14,260 & 7.6 \\
1995 & 11,737 & 7.9 \\
2000 & 8,814 & 6.1 \\
2005 & 6,574 & 5.4 \\
\hline
\end{tabular}

sociated with a $30-50 \%$ reduction in neonatal mortality [18]. It has also been suggested that to counter the effects of socioeconomic deprivation, interventions during pregnancy alone are insufficient and that interventions need to be introduced prior to conception $[19,20]$.

Two recent studies of multivitamin supplementation during pregnancy have shown a positive effect. A study of over 8,000 pregnant women in Tanzania showed a significant reduction in the incidence of LBW infants from 9.4 to $7.8 \%$ [21]. A study of over 30,000 pregnant women in Indonesia showed a significant reduction in early infant mortality and a trend towards reduction in the incidence of LBW infants [22].

\section{Cuban Experience}

The percentage of LBW births in Cuba is lower than both in neighbouring countries such as Jamaica and far richer countries such as the UK and USA. The percentage of LBW births in Cuba has consistently fallen over the last 30 years (table 3) [23]. The worldwide incidence of LBW births in developing countries over the last decade has remained relatively constant $(24 \%$ in 1990 and $23 \%$ in 2000) [1]. Cuba has an excellent healthcare system and, in particular, has a primary healthcare system which is the envy of many countries.

The primary healthcare system is based around the family doctor who is located in a small primary care centre (consultorio) where there is also a nurse [24]. Both the nurse and family doctor live either at the primary care centre or nearby. Each family doctor and nurse provide medical care for between 120 and 160 families. The family doctor and nurse see individual patients at least twice a year for a routine check-up. One check-up occurs within the primary care clinic and the other at the patient's home. 
Table 4. Prevalence of LBW births at two different times (1990 [29] and 2000 [1])

\begin{tabular}{llc}
\hline & 1990 (UNICEF 1996 report) & 2000 \\
\hline Finland & 4 & 4 \\
Cuba & 9 & 5 \\
UK & 7 & 8 \\
USA & 7 & 8 \\
Jamaica & 11 & 9 \\
Bangladesh & 50 & 30 \\
India & 33 & 30 \\
\hline
\end{tabular}

The primary care health team are aware of each patient's medical and social problems. This system results in the early identification of patients with social problems that may adversely affect their health. It allows health professionals to give appropriate advice to women who are likely to become pregnant prior to conception. Within the primary care system there is a strong emphasis on the importance of nutrition for women during pregnancy and while breastfeeding. Such a system provides excellent internatal care which has been identified as probably being more important than antenatal care [19].

During pregnancy, each woman receives 12 checkups. If it is a low-risk pregnancy, then the woman will be seen each month by the family doctor who will check her weight and blood pressure alongside a physical examination appropriate for the stage of the pregnancy. For pregnancies where there is a higher risk, the family doctor will liaise with appropriate specialists such as obstetricians, dieticians, and psychologists and ensure that the pregnant woman is seen by both the family doctor and appropriate specialists as frequently as is required.

For women with major social problems (including teenage pregnancies) the Cuban healthcare system has established maternity homes. These are buildings that offer free food and accommodation for pregnant women from 20 weeks' gestation. A doctor, midwife and nurse provide medical care during the day and the women are provided with healthy meals and advice regarding nutrition and breastfeeding. In a country where there is an acute shortage of housing and young adults often live with their parents, teenagers who are pregnant welcome the opportunity of living with other teenagers who are also pregnant. Mothers who are expecting twins are also offered the opportunity of staying in the maternity home from 20 weeks' gestation, and in a society where women are still expected to do all domestic chores this offer is usually accepted as it gives the pregnant woman the opportunity of resting.

Cuba also has an excellent education system with free and universal education for all children between the ages of 6 and 16 years. This ensures that all women receive education, which is an important factor in reducing the risk of a LBW baby. Cuba has a 100\% literacy rate [25] and has attained the two Millennium Development Goals that relate to education (ensuring all boys and girls complete a full course of primary schooling and the elimination of gender disparity in primary and secondary education) [26].

Cuba is a poor country (currently ranked as 120th worldwide). There is increasing recognition that poverty and poor socioeconomic conditions are relative and not absolute. Countries with higher levels of income inequality, such as the USA and UK, have higher rates of LBW babies than countries with lower levels of income inequality [27]. The relationship between income inequality and health and nutrition is complex. It is highly likely that the impact of income inequality is multifactorial and relevant factors include access to healthcare, education, mental health problems and diet [28]. The prevalence of LBW infants has actually increased in both the UK and USA (table 4), whereas it has decreased or remained static in countries such as Finland, which have lower levels of income inequality $[1,29]$. Cuba has less income inequality than many other countries and this is probably a contributory factor to its low LBW rate. Cuba also has a national subsidy on essential foods which helps to reduce malnutrition.

\section{Conclusions}

Reducing the number of LBW infants that are born worldwide is essential if the Millennium Development Goals are to be achieved. Lessons can be learnt from Cuba in reducing the rate of LBW infants. A free and universal healthcare system with an emphasis on primary healthcare is probably the major factor. Alongside this, targeted nutrition and education in women who are of child-bearing age are likely to have a significant impact. Political measures such as reducing poverty and income inequalities are also likely to significantly reduce both the number of LBW infants and child mortality. Finally, one needs to recognise that a small increase in mean birth weight within disadvantaged communities can have a significant impact on both neonatal and infant mortality. 


\section{References}

1 UNICEF/WHO: Low Birth Weight: Country, Regional and Global Estimates. New York, UNICEF, 2004.

2 Matthews TJ, MacDorman MF: Infant Mortality Statistics from the 2004 Period Linked Birth/Infant Death Data Set. National Vital Statistics Reports, vol 55, No 15. Hyattsville, National Center for Health Statistics, 2007.

3 WHO: World Health Statistics. Geneva, WHO, 2007.

4 Spencer $\mathrm{N}$ : The effect of income inequality and macro-level social policy on infant mortality and low birth weight in developed countries - a preliminary systematic review. Child Care Health Dev 2004;30:699-709.

5 Kramer MS: Determinants of low birth weight: methodological assessment and meta-analysis. Bull WHO 1987;65:663-737.

-6 Smith LK, Draper ES, Manktelow BN, Dorling JS, Field DJ: Socioeconomic inequalities in very preterm birth rates. Arch Dis Child Fetal Neonatal Ed 2007;92:F11-F14.

-7 Luo ZC, Wilkins R, Kramer MS, for the Fetal and Infant Health Study Group of the Canadian Perinatal Surveillance System: Effect of neighbourhood income and maternal education on birth outcomes: a population-based study. CMAJ 2006;174:1415-1420.

$\checkmark 8$ Goldenberg RL, Culhane JF, Iams JD, Romero R: Epidemiology and causes of preterm birth. Lancet 2008;371:75-84.

9 Green NS, Damus K, Simpson JL, et al: Research agenda for preterm birth: recommendations from the March of Dimes. Am J Obstet Gynecol 2005;193:626-635.

$>10$ Collier SA, Hogue CJR: Modifiable risk factors for low birth weight and their effect on cerebral palsy and mental retardation. Matern Child Health J 2007;11:65-71.
11 Ofori BD, Le Tiec M, Bérard A: Risk factors associated with preterm birth according to gestational age at birth. Pharmacoepidemiol Drug Saf 2008;17:556-564.

12 Lu MC, Lin YG, Prietto NM, Garite TJ: Elimination of public funding of prenatal care for undocumented immigrants in California: a cost/benefit analysis. Am J Obstet Gynecol 2000;182:233-239.

13 Bobak M: Outdoor air pollution, low birth weight, and prematurity. Environ Health Perspect 2000;108:173-176.

14 Šrám RJ, Binková B, Dejmek J, Bobak M Ambient air pollution and pregnancy outcomes: a review of the literature. Environ Health Perspect 2005;113:375-382.

15 Gulmezoglu M, de Onis M, Villar J: Effectiveness of interventions to prevent or treat impaired fetal growth. Obstet Gynecol Surv 1997;52:139-148.

16 Villar J, Gulmezoglu M, Metin A, de Onis M: Nutritional and antimicrobial interventions to prevent preterm birth: an overview of randomized controlled trials. Obstet Gynecol Surv 1998;53:575-585.

17 Ceesay SM, Prentice AM, Cole TJ, et al: Effects on birth weight and perinatal mortality of maternal dietary supplements in rural Gambia: 5-year randomised controlled trial. BMJ 1997;315:786-790.

18 Shrimpton R: Reducing childhood mortality in poor countries. Preventing low birth weight and reduction of child mortality. Trans R Soc Trop Med Hyg 2003;97:39-42.

19 Lu MC, Kotelchuck M, Culhane JF, et al: Preconception care between pregnancies: the content of internatal care. Matern Child Health J 2006;10:S107-S122.
20 Haas IS, Fuentes-Afflick E, Stewart AL, et al: Prepregnancy health status and the risk of preterm delivery. Arch Pediatr Adolesc Med 2005; 159:58-63.

21 Fawzi WW, Msamanga GI, Urassa W, et al: Vitamins and perinatal outcomes among HIV-negative women in Tanzania. N Engl J Med 2007;356:1423-1431.

22 The Supplementation with Multiple Micronutrients Intervention Trial (SUMMIT) Study Group: Effect of maternal multiple micronutrient supplementation on fetal loss and infant death in Indonesia: a doubleblind cluster-randomised trial. Lancet 2008; 371:215-227.

23 http://www.sld.cu/sitios.de (accessed December 19, 2007)

24 Dresang LT, Brebrick L, Murray D, Shallue A, Sullivan-Vedder L: Family medicine in Cuba: community-oriented primary care and complementary and alternative medicine. J Am Board Fam Pract 2005;18:297303.

25 UNICEF: The State of the World's Children. Child Survival. New York, UNICEF, 2008.

26 Pan American Health Organization (PAHO): Health in the Americas 2007. Sci Tech Publ 622. Washington, PAHO, 2007, vol 2, pp 262-279.

27 Pickett KE, Wilkinson RG: Child wellbeing and income inequality in rich societies: ecological cross sectional study. BMJ 2007;335: 1080-1085.

28 Wilkinson RG: The Impact of Inequality. How to Make Sick Societies Healthier. Abingdon, Routledge, 2005.

29 UNICEF: The State of the World's Children. New York, UNICEF, 1996. 